\title{
Novel Polysulfone/Carbon nanotube- \\ Polyamide Thin Film Nanocomposite \\ Membranes with Improved Water Flux for \\ Forward Osmosis Desalination
}

Ahmed O. Rashed ${ }^{a}$,Amal M. K. Esawi ${ }^{b, *}$, Adham R. Ramadan ${ }^{a}$

aDepartment of Chemistry, The American University in Cairo

AUC Avenue, New Cairo, Egypt

${ }^{b}$ Department of Mechanical Engineering, The American University in Cairo

AUC Avenue, New Cairo, Egypt 


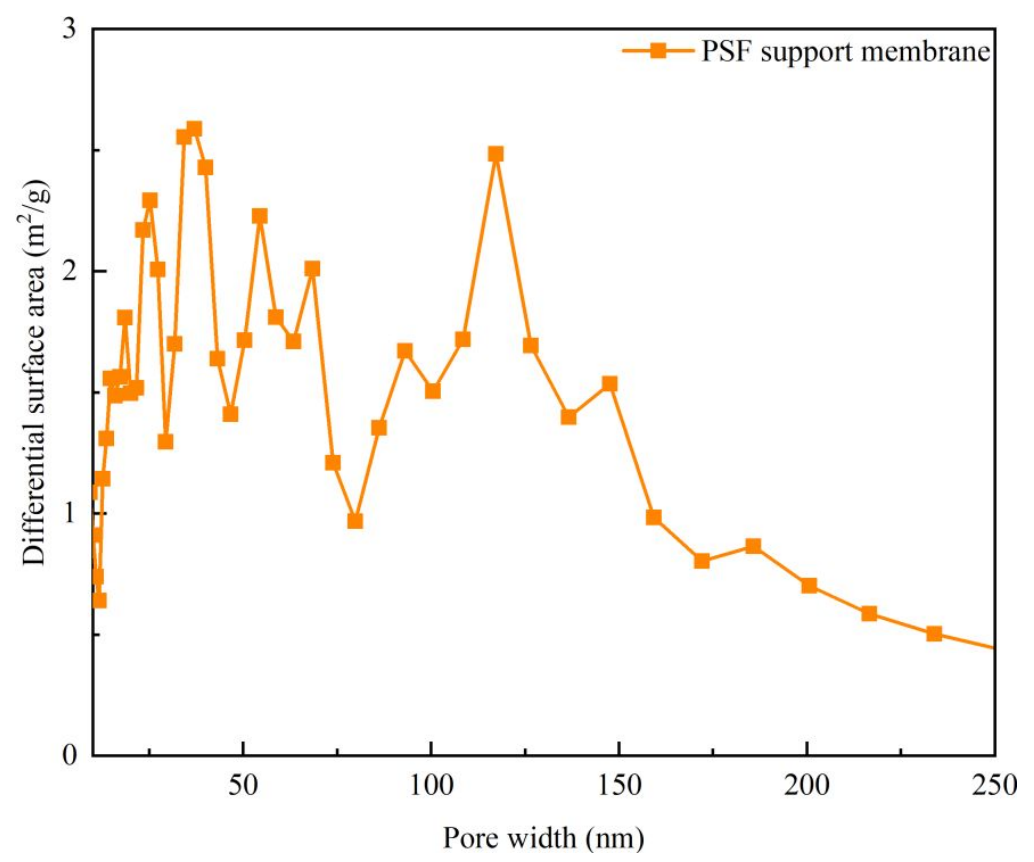

Figure S1. Plot of differential surface area vs. pore width for PSF support membrane, range $10-250 \mathrm{~nm}$.

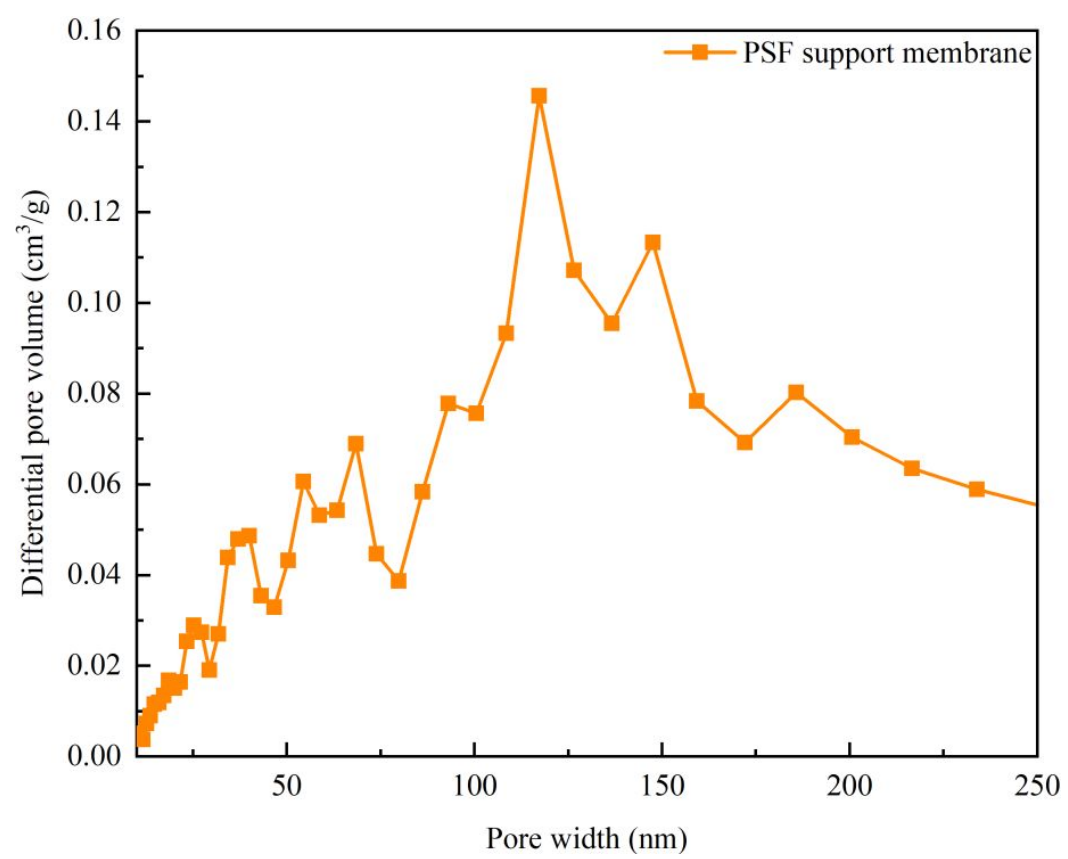

Figure S2. Plot of differential pore volume vs. pore width for PSF support membrane, range $10-250 \mathrm{~nm}$. 